\title{
RELAÇÕES EM CONFLITO: UMA PRÁTICA DE FORMAÇÃO TEATRAL NA COMUNIDADE
}

\author{
Profa. Dra. Márcia Pompeo Nogueira ${ }^{1}$ \\ PPGT; CEART/UDESC \\ marciapompeo@gmail.com
}

\section{Elementos Históricos e Fundamentos do Trabalho}

O Núcleo de Formação de Facilitadores - FOFA - é um grupo de pesquisa e extensão que existe desde o final de 2008, no Centro de Artes da UDESC. Conta atualmente com cerca de 20 (vinte) integrantes, incluindo um grupo de pessoas da universidade - alunos de graduação, entre eles bolsista, estagiários e voluntários; alunos de mestrado, que desenvolvem pesquisa nesta área, e a professora coordenadora do projeto - pessoas de fora da universidade - lideres comunitários e coordenadores de trabalhos teatrais em comunidades, escolas e sindicatos. A opção pelo teatro em comunidades surge, para alguns, como evolução de uma prática teatral, que busca uma interação com um contexto específico, para outros, surge de uma atuação comunitária, que busca no teatro um caminho para ampliar seu vínculo com a comunidade. Tanto num caso como no outro há a necessidade de se debater o fazer teatral em comunidades.

A diversidade que caracteriza a história de vida de cada um de seus integrantes é o que tem de mais rico no FOFA. Esse fórum de teatro na comunidade vincula pesquisa e extensão e representa um espaço de troca, na medida em que favorece a experimentação e o debate. As reuniões do grupo acontecem semanalmente, nelas desenvolvemos atividades diversas: investigamos metodologias relacionadas ao teatro em comunidades e dialogamos sobre os desafios dessa modalidade teatral. 


\section{Fundamentos do Trabalho}

A linha condutora dos trabalhos no FOFA segue a abordagem Dialógica do Teatro para o Desenvolvimento, principalmente no sentido de valorizar as vozes das comunidades na construção de processos criativos.

O Teatro para o Desenvolvimento refere-se a práticas que possuem uma clara perspectiva de transformação. Baseada em estudos sobre as políticas de desenvolvimento, analisei ${ }^{2}$ diferentes modalidades desse tipo de teatro, que me possibilitaram identificar que a principal diferença entre elas é o ponto de vista de quem as propõe. De um lado existem abordagens cujos objetivos são decididos de cima para baixo. Nelas, agentes externos que, mesmo sem conhecer a realidade específica em que vão atuar, acreditam saber o que é melhor para determinadas comunidades, o que deve ser mudado e como. Nesta perspectiva a transformação é proposta para o “outro". Os agentes externos se identificam como aqueles que devem planejar as soluções certas para os problemas "dos outros".

Práticas variadas podem ser identificadas nessa abordagem: uma delas, o agitprop ${ }^{3}$, perspectiva bastante conhecida que moldou o entendimento de muitas pessoas em termos do que pode ser um teatro político, é caracterizada principalmente por um teatro que divulga mensagens revolucionárias; a outra abordagem, que chamei de devprop ${ }^{4}$, é caracterizada pela proposição de alternativas técnicas para solucionar problemas específicos. Segundo Jacques Mda, a dependência de soluções técnicas, característica deste paradigma, é a exclusão do exame de qualquer fator estrutural que contribua para o entendimento o problema. $\mathrm{O}$ agente externo superior decide, baseado somente no nível técnico, como melhor resolver os problemas de comunidades específicas e cria seus próprios planos para facilitar a solução. Nenhuma tentativa é feita de consultar as comunidades antes que os planos sejam formulados (MDA, 1993, p. 125). Existem vários exemplos na literatura dessa área, entre eles as práticas voltadas para ensinar o uso de pesticidas na lavoura (KIDD, 1984) ou as que ensinam a fazer latrinas ventiladas (MDA, 1993). 
De outro lado, situa-se a principal formulação crítica das abordagens de cima para baixo, fundamentada no argumento de que representam uma invasão cultural, uma imposição de uma visão de mundo sobre outra. Esta concepção crítica é chamada de abordagem Dialógica do Teatro para o Desenvolvimento. Fundamenta-se primordialmente em Paulo Freire, que entende que relações desiguais fazem parte de um processo de desumanização para ambos os lados: aquele que tem sua humanidade roubada, tratado como objeto: o oprimido, mas também para o opressor que deixa de se tornar totalmente humano. (FREIRE, 1979, p. 16) Freire propõe que no lugar de tratar as pessoas das comunidades como objetos, devem-se tratá-las como sujeito.

A abordagem Dialógica do Teatro para o Desenvolvimento representa um espaço de encontro, com ou sem a presença de um facilitador externo, para que explorem democraticamente a linguagem teatral, enquanto um dos passos possíveis para imaginar e criar as mudanças desejadas na comunidade. São projetos criativos, partindo sempre do ponto de vista de seus integrantes, que visam ao fortalecimento das comunidades e à ampliação do diálogo entre os seus diferentes segmentos. Nesses projetos, a perspectiva política é diferente das mensagens transformadoras, o foco aqui é descobrir, articular e dar forma para conteúdos, problemas ou histórias significativas para as pessoas da própria comunidade, como um passo importante na solução de problemas, no enfrentamento de dificuldades, e/ou na construção de um mundo melhor.

\section{Como entrar numa Comunidade?}

No início do segundo semestre de 2009, havia no FOFA uma demanda de atuação conjunta em comunidades. A ideia era desenvolver trabalhos com as diversas comunidades coordenadas por membros do FOFA. Escolhemos, entretanto, a comunidade da Tapera como a primeira a ser foco de um trabalho conjunto. Quem coordenava o trabalho teatral na Tapera era Filipe Ferreira, o mais novo membro do FOFA que, nessa época tinha 16 anos, e havia um desejo no núcleo de fortalecimento deste trabalho. 
A entrada numa comunidade, segundo o método Dialógico de Teatro para o Desenvolvimento, exige a preparação do grupo de facilitadores em termos do seu papel na interação com uma comunidade, que não se confunde com o do especialista, que vem com o trabalho pronto. Sua tarefa é de estabelecer um diálogo com a comunidade como condição para o desenvolvimento de um trabalho teatral:

No lugar de dar direções, o facilitador deve dialogar com a comunidade para identificar os principais problemas e preocupações. Seguindo a proposta de coringa do Boal, o facilitador deve fazer perguntas, no lugar de dar respostas, encorajando as pessoas da comunidade para encenar suas ideias, ajudando a manter o foco no problema e nas formas de solucioná-lo. Abrindo espaço para que diferentes setores da comunidade compartilhem seus entendimentos em relação ao assunto, e garantindo a democracia do processo. (NOGUEIRA, 2002)

Existem duas modalidades básicas do Teatro Dialógico: o teatro "com" comunidade e o teatro "pela" comunidade. O primeiro envolve uma pesquisa sobre os temas de interesse da comunidade, antes da criação do drama, mas os facilitadores criam o trabalho teatral sobre estes temas, fora da comunidade. Depois de pronto o espetáculo, eles retornam para apresentá-lo à comunidade e debater seu significado. O teatro feito "pela" comunidade representa um processo que envolve a comunidade em todo o processo criativo, inclusive a encenação que é baseada nos temas escolhidos pelos participantes.

Os antigos 'objetos' de pesquisa e de comunicação num sentido único eram integrados no processo de pesquisa e aprendizagem enquanto 'sujeitos' da experiência. No lugar de retornarem para o centro depois da pesquisa de campo, o grupo de fora fica na comunidade e desenvolve a análise e a dramatização com os moradores da comunidade. No lugar de fazer algumas peças para o povo, eles dão assistência ao povo para eles mesmos fazerem as 'peças'. (KIDD, 1984, p. 6-7)

O método dialógico nos oferece um referencial de interação com a comunidade que envolve diferentes etapas. Vamos nos ater, aqui neste estudo, às duas primeiras, que dizem respeito especificamente à forma de se entrar numa comunidade.

Na primeira, é exigida do facilitador uma atitude diferente do agente externo que chega numa comunidade, fala com as autoridades locais, faz perguntas gerais e vai embora, o chamado "turista de desenvolvimento". Na abordagem Dialógica do Teatro para o Desenvolvimento, 
enquanto acontece a pesquisa na comunidade, a atenção deve estar voltada para formas de conhecer a comunidade e as pessoas que moram nela. Esse método exige mais tempo com os moradores do local para que a aprendizagem seja gradual. Num exemplo presente na bibliografia ${ }^{6}$, chamado de transect-walk, os facilitadores são divididos em pares e caminham pela comunidade, conversando com as pessoas que encontram, visitando instituições como escolas, postos de saúde, onde adquirem a primeira impressão sobre a comunidade e convidam todos para uma reunião (ibid: 22). Esse método representa uma aproximação informal com o cotidiano da comunidade e favorece o relacionamento com diferentes setores: crianças, jovens, idosos, mulheres e homens. Ele permite ao facilitador ir além das vozes mais articuladas e oficiais, visitando a periferia, o comércio local e pode gerar um entendimento mais amplo do que é a comunidade.

\section{O FOFA na Tapera}

Nossa apropriação do método dialógico foi encaminhada na comunidade da Tapera. Sugerimos que a atividade envolvesse todos os integrantes dos dois grupos: o FOFA e o grupo da Tapera, sendo que o primeiro deveria ser guiado pelo segundo. Pedimos que o grupo da Tapera escolhesse os caminhos que gostaria de levar os membros do FOFA. Deixamos claro que nosso interesse não era o do turista que só quer usufruir dos lugares mais bonitos. Queríamos conhecer mais profundamente a comunidade.

Na nossa primeira visita à Tapera, o grupo de lá conseguiu o espaço do salão da Igreja Católica para trabalharmos e preparou caminhos da comunidade para nos levar. O trabalho tinha o objetivo de integrar os dois grupos. A proposta era formar duplas de gente do FOFA e pessoas da Tapera, para favorecer nossa integração. Trocamos algumas vezes de par e no final sintetizamos nosso conhecimento sobre cada pessoa ali presente. O grupo da Tapera era formado majoritariamente por meninas, com idades entre 10 e 14 anos. Dançamos juntos e em seguida nos dividimos em grupos e fomos guiados por eles pelos “Caminhos da Tapera”. A proposta era registrar o caminho com máquinas fotográficas que passavam pelas mãos dos integrantes do FOFA e da Tapera; e colher cheiros, barulhos e objetos significativos que encontrávamos no caminho. 
Conversamos com alguns moradores que encontramos no caminho, descobrindo elementos da história da comunidade.

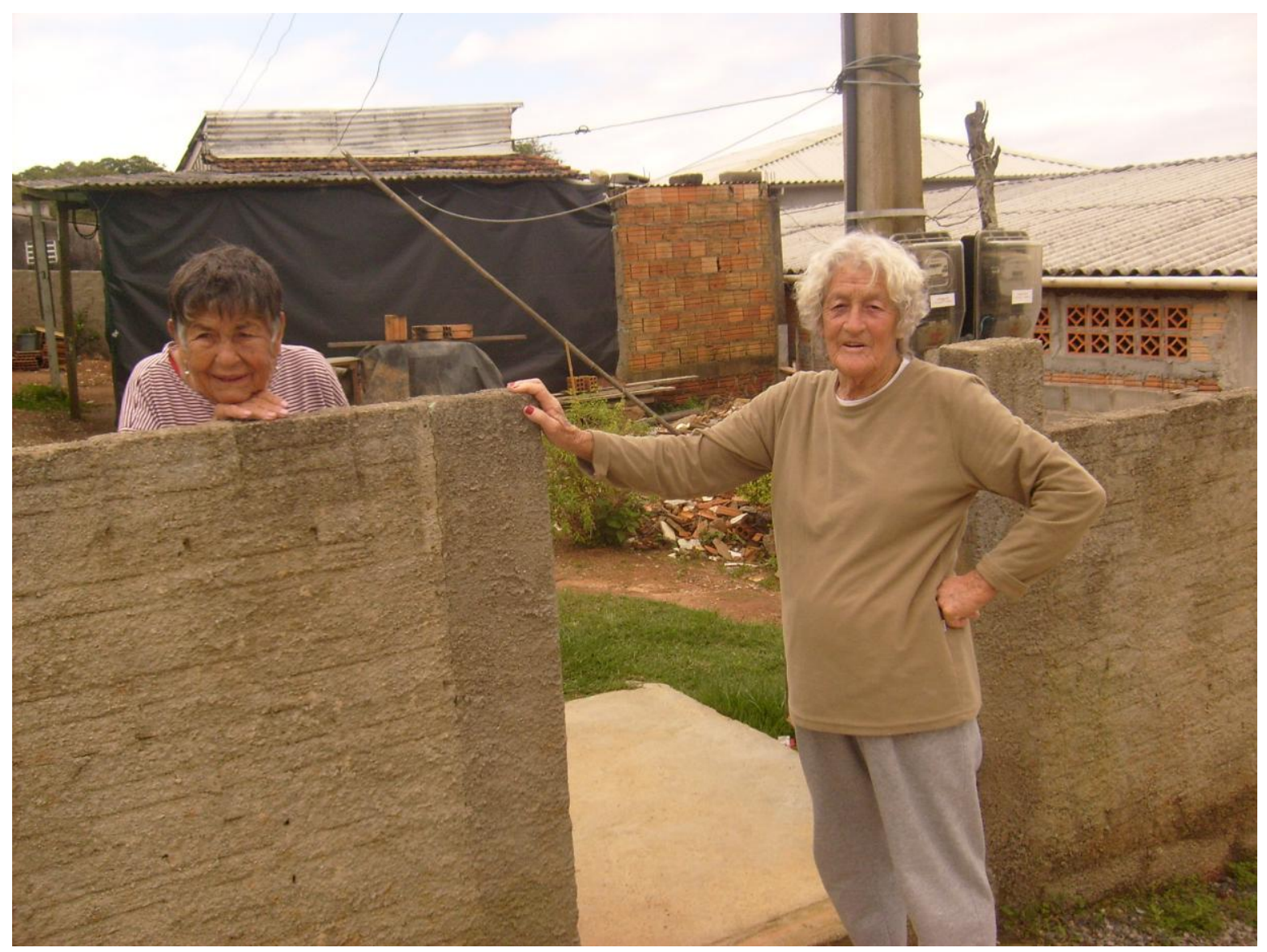

Imagem 1: Nos Caminhos da Tapera conversamos com alguns moradores que encontramos no caminho, descobrindo elementos da história da comunidade. 


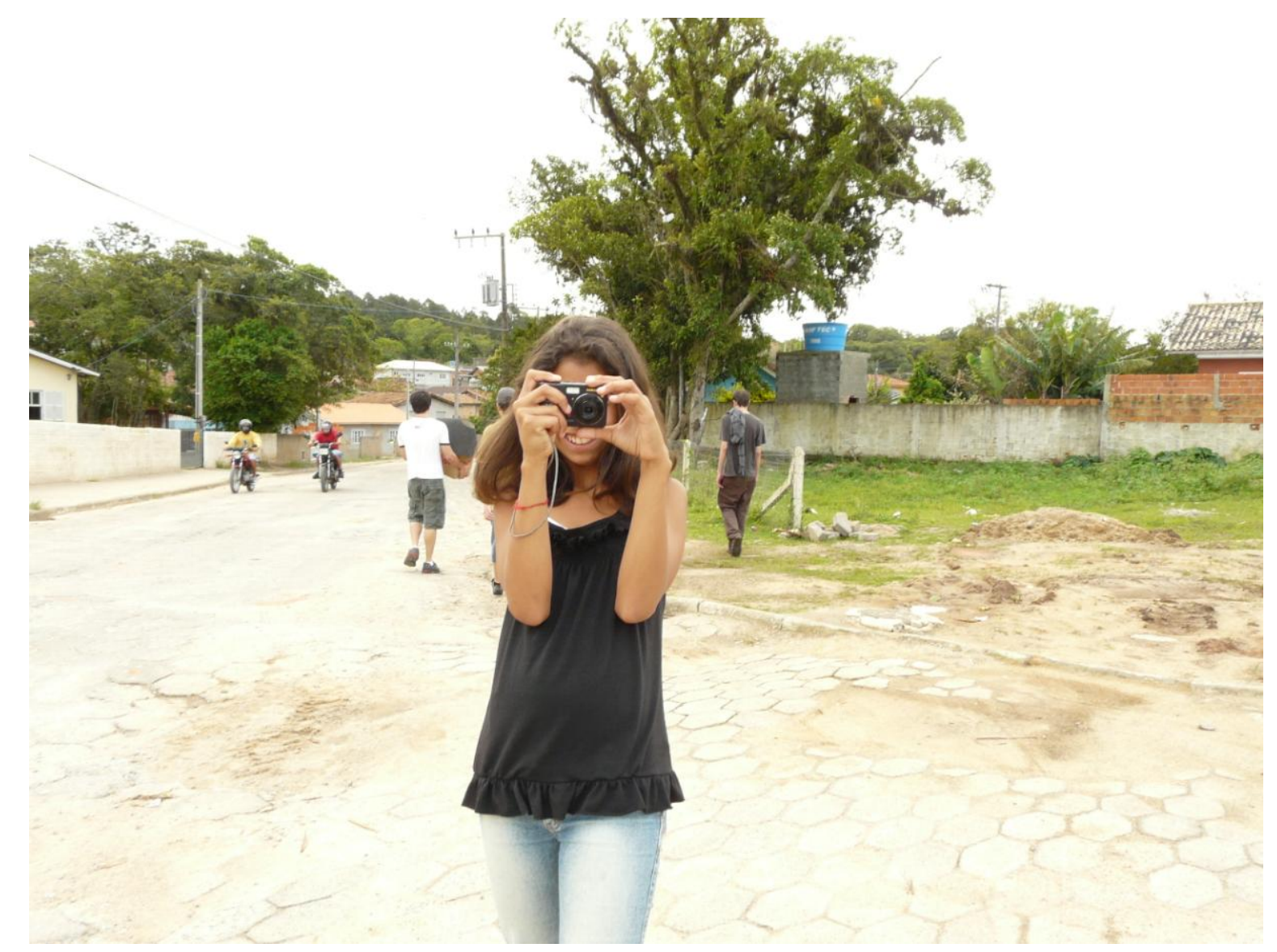

Imagem 2: A proposta era registrar o caminho com máquinas fotográficas que passavam pelas mãos dos integrantes do FOFA e da Tapera

Apesar de nossa recomendação, a maior parte dos grupos foi guiada para caminhos próximos à praia da Tapera, um local muito bonito, mais rico e menos populoso da comunidade. Apenas um dos grupos foi para a "Rua do Juca", um local menos turístico onde os problemas da comunidade ficavam mais a mostra. Nesse caminho conversamos sobre o tráfico de drogas que acontece na comunidade, e que fica mais evidente de noite. Nossa guia nos contou da morte de jovens da comunidade relacionados com o tráfico, dos problemas com o meio ambiente, de como o esgoto das casas é canalizado para a praia, poluindo o local mais lindo da comunidade. $\mathrm{Na}$ volta desse caminho nos deparamos com o portão da Base Aérea, uma abertura vigiada para um lado da comunidade restrito aos militares da Aeronáutica. A escola da comunidade fica dentro da Base Aérea. No final do dia, dançamos juntos novamente e nos despedimos. 


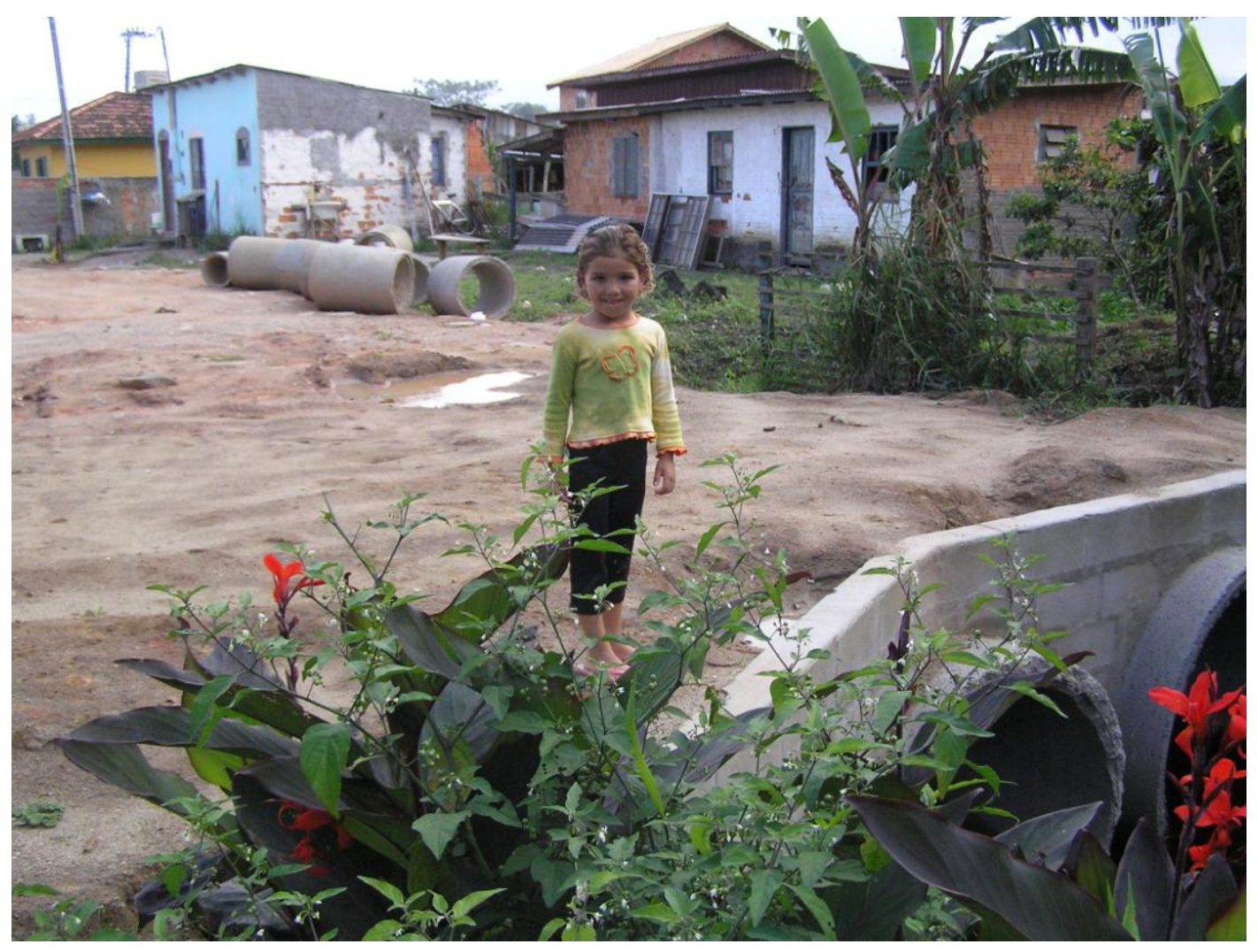

Imagem 3: Foto tirada na "Rua do Juca"

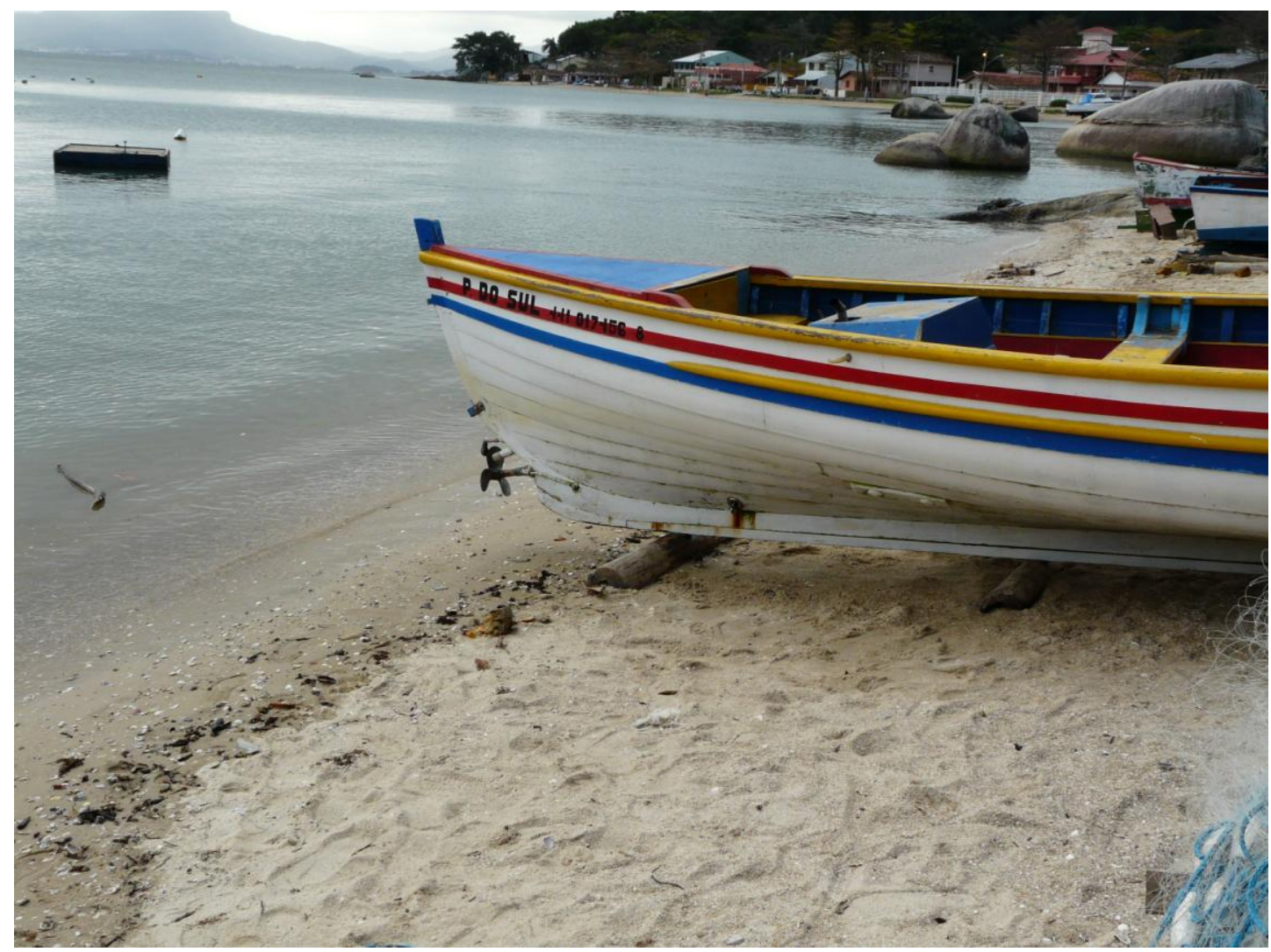

Imagem 4: "Praia da Tapera" 


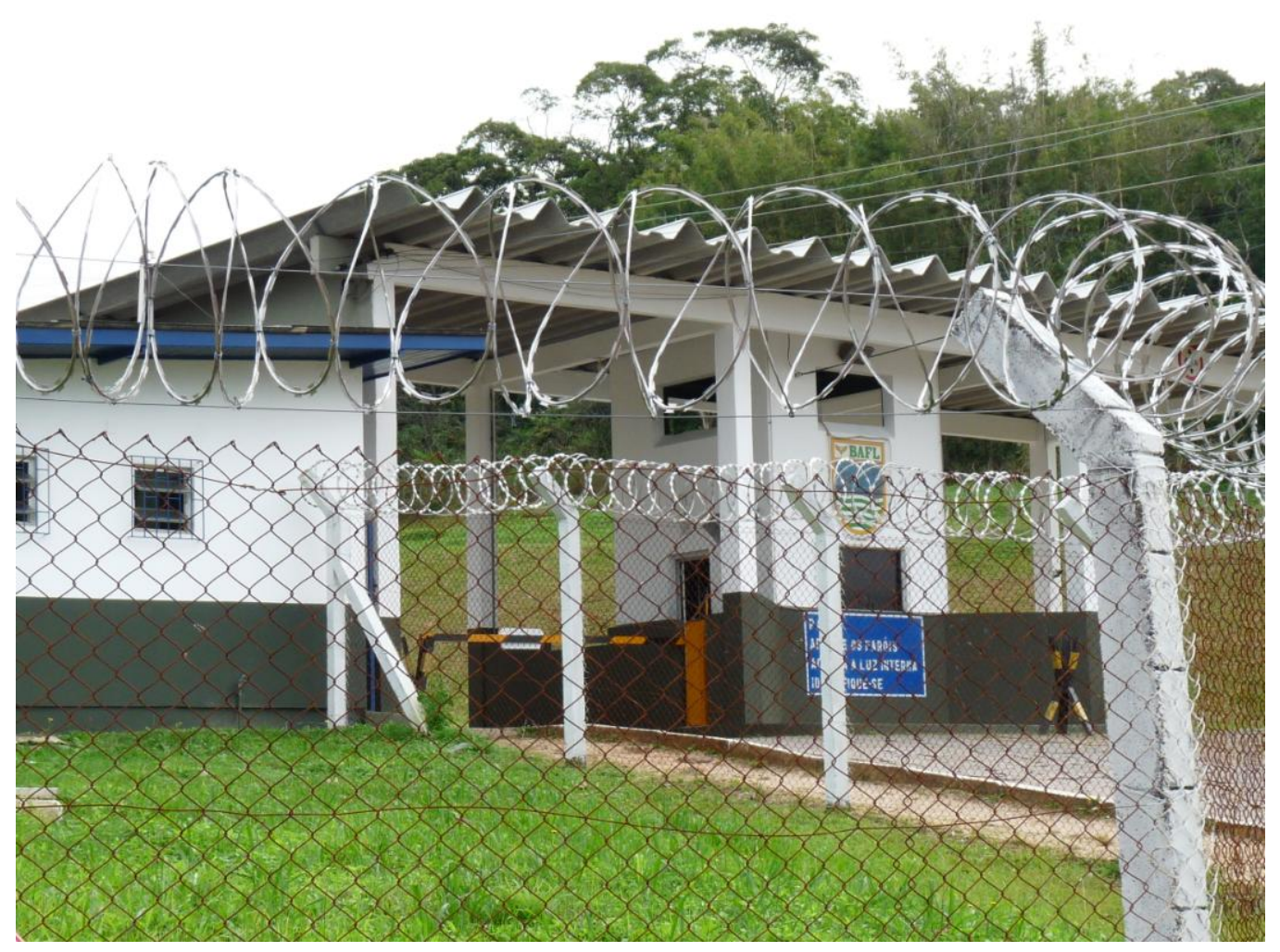

Imagem 5: Portão da Base Aérea, comunidade da Tapera

$\mathrm{Na}$ universidade, o FOFA analisou os dados coletados. Escolhemos as fotos mais representativas. Filipe participou da avaliação. Uma foto de um carro abandonado e dilapidado nos foi apresentada por Filipe como o símbolo de sua comunidade. Aos poucos fomos aprofundando nosso conhecimento sobre a Tapera.

Além da abordagem Dialógica do Teatro para o Desenvolvimento, outro referencial teórico/metodológicos guiou nosso trabalho: a proposta "dos caminhos da comunidade" desenvolvido por Ilo Krugli no seu trabalho com o Teatro Ventoforte.

O trabalho com os caminhos, para Ilo Krugli, parte do desenho no chão dos diferentes caminhos percorridos no cotidiano das crianças. Elas são estimuladas a imaginar, e depois desenhar os lugares de silêncio, os barulhentos; as cores; as temperaturas; as pessoas que encontram, etc. Esta sensibilização sensorial que antecede os desenhos permite um aprofundamento dos trabalhos. De um lado se aciona a memória, de outro a imaginação. (NOGUEIRA, 2008, p.123) 
Ilo Krugli fala que contar uma história tem semelhanças com os caminhos. Um mesmo começo, meio e fim. Cada caminho é, na verdade, uma história, simboliza uma experiência de vida. (ibid: 124) Através dos caminhos, as histórias são situadas nas suas comunidades, nos seus referenciais culturais.

Depois de feitos os caminhos, pergunta-se sobre "histórias de mentira e histórias de verdade" que acontecem nos caminhos desenhados. Esta proposta favorece uma interessante relação entre fantasia e realidade. É uma chave que abre a passagem para o imaginário do grupo. O contato com imagens simbólicas, com o imaginário dos participantes não representa uma fuga da realidade, ao contrário, aproxima-se do conceito proposto por Lucian Boia para quem "imaginário" não pode ser definido como algo que acontece fora da realidade concreta:

Imaginário em um sentido se mescla com a realidade, em outro, se confronta com ela. Ele age sobre o mundo e o mundo age sobre ele. Contudo, como parte de sua essência, é feito de uma realidade independente, com sua própria estrutura e sua própria dinâmica. [...] Para levar ao imaginário (pelo menos para sua expressão mais estruturada), a imaginação deve ser fertilizada pela racionalidade (BOIA 1998, p. 16-17)

Convidamos o grupo da Tapera para um workshop sobre caminhos, na universidade. Nesse dia voltamos a dançar juntos e propus que andassem pela sala refazendo mentalmente o caminho que fazem de suas casas para a escola, conforme a proposta de Ilo Krugli. Depois de desenhar num papel craft esses caminhos e suas casas, propus que inserissem algumas das fotos reveladas, das que tiramos no encontro anterior. Foi interessante notar que a maior parte das fotos era bem distante das casas das pessoas do grupo. Concluímos que fomos levados por caminhos que não são os caminhos do cotidiano das pessoas do grupo. 


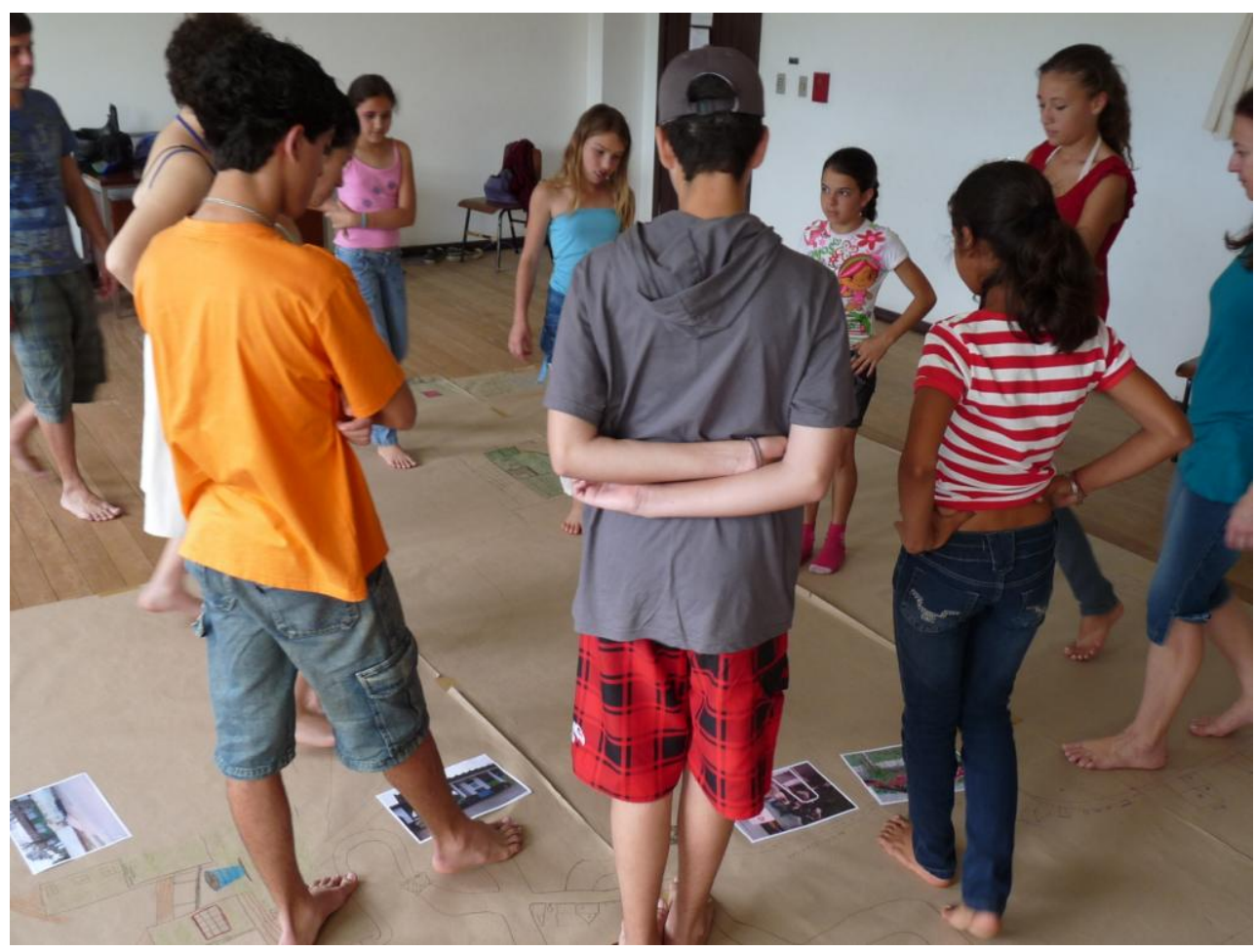

Imagem 6: Avaliando os "Caminhos da Tapera" descobrimos que a maior parte das fotos era bem distante das casas das pessoas do grupo

O passo seguinte foi pedir que desenhassem histórias de mentira e histórias de verdade que aconteceram nesses caminhos. As histórias contadas eram todas trágicas: atropelamentos, marido que mata a mulher, carro que pega fogo, mas as histórias eram no geral muito esquemáticas. Uma história chamou nossa atenção por envolver mais facetas de um problema: era a história de dois meninos que saíram da aula de judô, que acontece dentro da Base Aérea, e encontram um menino sozinho brincando. Era um menino que eles chamavam de "índio", com quem costumavam brigar na escola. Tentando mostrar as habilidades adquiridas no judô, resolvem bater no "índio". No meio da briga chega o pai do "índio", caracterizado como doido pelo narrador, que ao ver o seu filho apanhando, resolve bater nos meninos do judô. Um deles foge e o pai bate no que ficou, violentamente, até que a mãe do "índio" chega e diz para seu marido: chega! Ele é só uma criança...

Esta história nos interessou desenvolver. Mesmo sem saber se era uma história de mentira ou uma história de verdade, identificamos nela uma codificação, nos moldes freireanos. Era a codificação relativa a um problema que vem ganhando destaque, mas que ainda é muito pouco aprofundado, o bullying. Mais do que isso, a história integrava o problema da violência no contexto das crianças e dos adultos, permitindo um maior aprofundamento do problema. Acima de tudo, era 
uma história que, independentemente de ser real ou imaginária, foi situada pelo grupo como uma história da Tapera, que aconteceu nos seus caminhos.

Dessa forma, a terceira referência teórica no trabalho do FOFA é o conceito de codificação de Paulo Freire. Codificação representa uma forma de focar o diálogo - entre os facilitadores e os membros da comunidade envolvidos no projeto - objetivando desvelar a realidade, o que inclui aspectos objetivos e subjetivos. Codificação é feita de situações de vida.

A codificação representa uma dada dimensão da realidade da forma como é vivida pelo povo, esta dimensão é proposta para ser analisada num contexto diferente do que ela é vivida. Neste sentido, a codificação transforma o que era uma forma de vida num contexto real, num 'objeto' no contexto teórico (FREIRE 1979, p. 32).

Segundo Paulo Freire, a "codificação" permite aos participantes uma percepção distanciada de sua vida cotidiana, que pode ser admirada, isto é, observada a distância, transformada em um objeto que pode ser coletivamente analisado. A codificação funciona como uma ponte entre os contextos teórico e prático. Uma imagem da realidade concreta é um ponto de partida para uma análise abstrata que pode desvelar profundos relacionamentos dos atores sociais que passam freqüentemente despercebidos. (NOGUEIRA, 2003, p.27)

Para nós, a briga dos meninos do judô com o "índio" é uma codificação. No entanto, esta codificação nasceu de uma investigação que inclui elementos imaginários. A história não surge de uma conversa racional sobre o que identificamos como problemas. Ela surge de um jogo que mistura verdades e mentiras, mas é identificado a partir de uma história que nasceu nos "Caminhos da Tapera”. A mudança do contexto real para o contexto imaginário - dado pela alternativa de um mundo fantástico, fundado na mentira, proposto no jogo - desloca a situação do fluxo do cotidiano, gera um distanciamento. Chamamos isso de "codificação imaginária"?.

Os temas que a história traz é a violência, o bullying, o preconceito. Interliga o âmbito do bullying na escola à violência do mundo dos adultos que entram na briga trazendo flagrantes de loucura, de um destempero.

Para Freire, a escolha de uma boa codificação é fundamental para o desenvolvimento de uma análise crítica frutífera. Freire apresenta as seguintes condições: 
Uma primeira condição a ser cumprida é que, necessariamente, devem representar situações conhecidas pelos indivíduos cuja temática se busca, o que as faz reconhecíveis por eles. [...] Igualmente fundamental para sua preparação é a condição de não poderem ter as codificações, de um lado, seu núcleo temático demasiado explícito; de outro, demasiado enigmático. [...] $\mathrm{Na}$ medida em que representam situações existenciais, as codificações devem ser simples na sua complexidade e oferecer oportunidades plurais de análise na sua descodificação, o que evita o dirigismo massificador da codificação propagandística. As codificações não são slogans, são objetos cognoscíveis, desafios sobre o que deve incidir a reflexão crítica dos sujeitos descodificadores (FREIRE, 1977, p. 127-128).

A codificação imaginária preenche esses requisitos. A história contada tinha elementos de uma codificação. Apresentava um problema bastante contemporâneo que tem sido trabalhado no mundo todo. Um problema que não é novo, mas que deixa marcas nas pessoas: o bullying.

O teatro é um meio especial para se explorar uma codificação. Para Freire, o processo de descodificação requer que se mova da parte ao todo e que retorne para a parte; do concreto ao abstrato e ao concreto novamente, parte de um constante fluxo e re-fluxo. Através desse processo é possível que se atinja uma perspectiva crítica da realidade concreta, anteriormente percebida como densa e impenetrável (ibid: 114).

A descodificação através da criação teatral permite que se investiguem os personagens, a história deles, seus gestus sociais. Nossa imaginação é acionada e as alternativas vão se concretizando, enquanto criamos uma nova codificação, relacionada com a primeira, mas mais profunda que ela: um espetáculo teatral.

Para nos ajudar no processo de descodificação, isto é, para aprofundar nosso entendimento do material que havíamos coletado, convidamos Sergio de Carvalho ${ }^{8}$. Pedimos a ele para nos ajudar a explorar as contradições nos dados coletados. Apresentamos dados de nossa investigação sobre a comunidade, as fotos, o desenho dos caminhos, a história escolhida para ser desenvolvida e analisada. Sergio fez algumas perguntas que ainda não estavam presentes no material que apresentamos a ele. Que religiões são ali praticadas? Do que vivem as pessoas da Tapera? Foi então que destacamos que se trata de uma comunidade que divide seu território com a Base Aérea de Florianópolis. Questões relativas a este relacionamento passaram a ser aprofundadas: o que as mulheres achavam dos homens da Base Aérea? Existe alguma rivalidade entre os homens da Tapera e os da Base Aérea? As respostas obtidas confirmavam as hipóteses de Sergio. Havia um paralelo muito interessante entre a realidade da Tapera e a peça Woyzeck, de George Büchner. 
Woyzeck, um texto incompleto escrito no século XIX, formado por cenas curtas, como explica Luiz Fernando Botelho:

\begin{abstract}
Última peça do dramaturgo alemão Georg Büchner (1), Woyzeck (1837) é exemplo interessante de texto inacabado que parece preservar o sentido de uma obra completa (...) $\mathrm{O}$ personagem-título é fuzileiro miliciano e age como se tivesse algum distúrbio mental que o imbeciliza. É servil, comunica-se de modo um tanto confuso e parece ter alucinações envolvendo uma ameaça que está prestes a atingir a região onde mora. Objeto de chacota e exploração de homens influentes - o médico, por exemplo, paga-lhe alguns trocados para utilizá-lo como cobaia de experiência alimentar - Woyzeck mantém relação afetiva com Marie, a quem entrega o pouco dinheiro que ganha. Ambos criam um bebê e vivem miseravelmente. A descoberta de que sua companheira mantém um caso com o tamboreiromor da milícia desconcerta Woyzeck, que entra numa espiral obsessiva que culmina com o assassinato de Marie, a quem ele esfaqueia até a morte. ${ }^{9}$
\end{abstract}

Da mesma forma que na Tapera, Woyzeck se passa numa base militar. Trabalhando o texto de Georg Büchner poderíamos lidar de forma distanciada a tensão entre a Tapera e a Base Aérea e o texto nos fornecia um elemento teatral interessante de ser desenvolvido teatralmente. Outro paralelo era a figura do louco, tanto Woyzeck como o pai da história da comunidade eram pessoas vistas como loucas.

Junto com a sugestão do texto Woyzeck, Sergio de Carvalho adicionou mais um elemento no nosso trabalho: o teatro dialético. Dessa forma, os quatro referenciais - abordagem dialógica do teatro para o desenvolvimento, trabalho dos caminhos proposto pelo Ventoforte, a proposta das codificações freireanas e o teatro dialético- estavam integrados na forma como desenvolvemos nosso projeto na "Comunidade da Tapera". Não chegamos com um projeto pronto, tentamos nos acercar da comunidade conhecendo seus caminhos e as pessoas que ali vivem, ouvimos as histórias desses caminhos e identificamos uma codificação relativa a um problema da comunidade, exploramos as contradições presentes nos dados coletados.

\title{
O Processo Criativo
}

Optamos por desenvolver uma montagem que fosse ao mesmo tempo um teatro feito "pelos" integrantes do grupo da Tapera ${ }^{10}$, como um teatro feito "com" a comunidade, isto é, os membros do FOFA $^{11}$ também desenvolveram parte do trabalho teatral ${ }^{12}$ Dessa forma, nosso trabalho foi misto: o grupo da Tapera desenvolveu as cenas relativas ao contexto da briga das crianças e os membros do 
FOFA desenvolveram seu trabalho sobre o contexto dos adultos, casando os dados coletados na comunidade e alguns elementos do texto do Woyzeck.

Uma vez identificado o tema bullying como foco de nossa codificação, enquanto facilitadores, passamos a pesquisar seu significado, envolvendo o grupo da Tapera na pesquisa. Identificamos os três tipos de atores que participam do problema: os agressores, as vítimas e as testemunhas, estas últimas também fazem parte do problema e sofrem com ele. Conversamos sobre as situações que enfrentam na sua escola, trabalhamos com imagens de bullying, retiradas da internet, como estímulo para o trabalho criativo. Procuramos desenvolver os personagens criados tentando fugir da polaridade maniqueísta do personagem bom e do personagem mau.

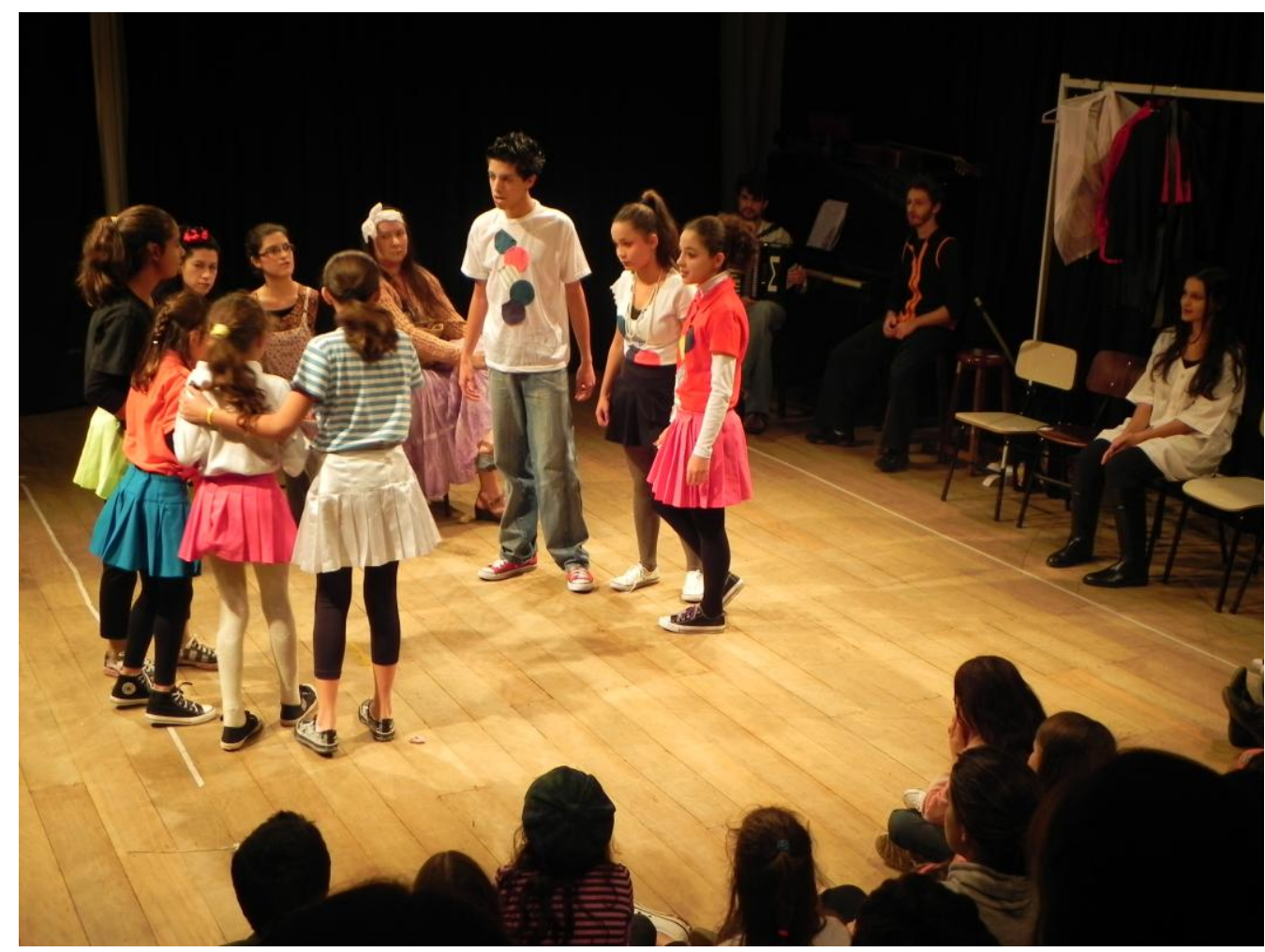

Imagem 7: Cena relativa ao contexto da briga das crianças

Já com o grupo do FOFA, avaliávamos o andamento dos trabalhos na comunidade ao mesmo tempo que nos dedicávamos à experimentação teatral relacionando cenas do texto Woyzeck com as informações que coletamos sobre a comunidade. Assim criamos a peça Relações em Conflito. Nela mantivemos alguns personagens do texto Woyzeck, como aqueles vinculados à base militar: Capitão, Tamboreiro-Mor. Por outro lado, criamos outros personagens para permitir o desenvolvimento de um paralelo com a realidade da Tapera. Aproximamos o personagem da Maria 
do Woyzeck com a mãe do "índio"; e do personagem Woyzeck com o pai do "índio". Entretanto, no lugar da fábula do texto Woyzeck, inserimos a nova fábula que assumimos como o centro do texto: a história contada pelas crianças. Mantivemos, no caso do Médico, os dados do texto em que Woyzeck faz parte, como cobaia, de uma pesquisa, em que é remunerado para só comer ervilhas. A loucura que fazia parte do pai do "índio" passa a ser justificada alegoricamente pela mesma razão que enlouquece o personagem de Buchner: comer apenas ervilhas. Não partimos, como chegamos a pensar, de uma pesquisa sobre o que "enlouquece" os pais de família na Tapera. Entendemos que a alegoria proposta pelo texto nos dava uma distância interessante para falar de situações opressivas vividas na luta pela sobrevivência.

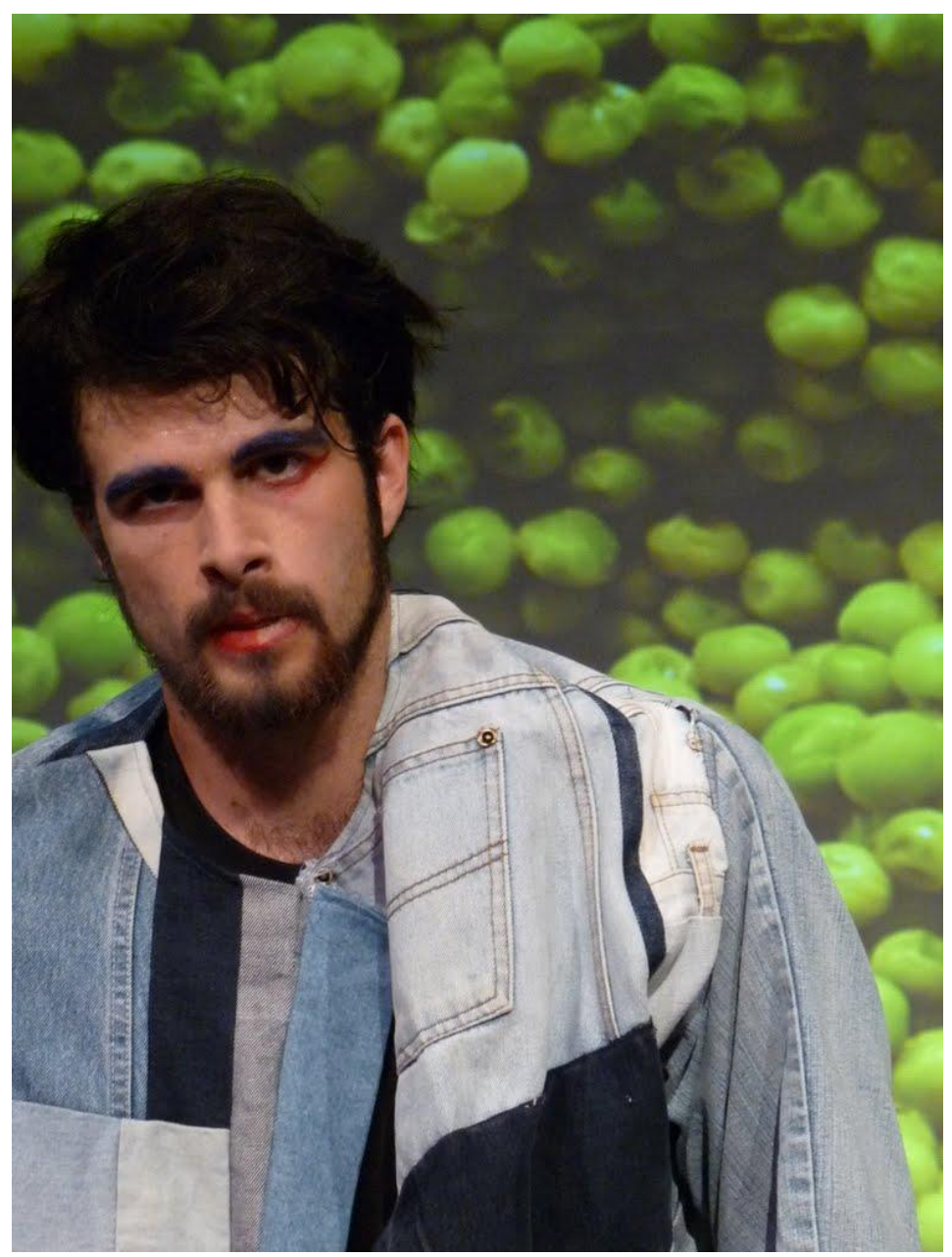

Imagem 8: Mantivemos, no caso do Médico, os dados do texto em que Woyzeck faz parte, como cobaia, de uma pesquisa, em que é remunerado para só comer ervilhas

Sobre o "índio" identificamos que não existem indígenas na Tapera. Que o apelido referia-se a uma depreciação do personagem. Uma pesquisa sobre relações étnicas na escola confirmou nossa hipótese: 
É preciso considerar os significados pejorativos da palavra índio, evocados por alguns alunos. Durante a aplicação do questionário, em duas classes, quando expliquei, em resposta a indagações, que os indígenas foram os primeiros habitantes do Brasil, as crianças mencionaram o termo "índio" como sinônimo e alguns meninos disseram "é isso que o fulano é" ou acusaram-se mutuamente de serem índios, dando risadas. Como as crianças apontadas não tinham qualquer traço indígena e o tom era de chacota, ficou subentendido que se tratava de um adjetivo ligado a ser bagunceiro, agitado, incivilizado. Ao comentar o fato, professoras lembraram-se de já ter utilizado a expressão "parecem um bando de índios" diante de classes desordeiras e levantaram a hipótese de que alguns meninos poderiam ter utilizado a classificação indígena apenas "de brincadeira". Não há grupos cultural ou etnicamente identificados como indígenas na área atendida pela escola. (CARVALHO, 2005)

Nossa hipótese foi transformada em cena, em meio às cenas de violência na escola, a professora chama seus alunos de "bando de índios" o que leva o grupo a se acusar mutuamente de "índios".

A peça Relações em Conflito incluía também algumas cenas conjuntas dos contextos das crianças e dos adultos, fazendo ligação entre os dois universos. Todo processo foi "regado" com muita música ${ }^{13}$ e danças populares. Elas estavam presentes desde o primeiro contato com a comunidade e trouxeram profundidade e leveza ao trabalho.

\section{Algumas Reflexões sobre o Teatro em Comunidade}

Nesse processo de montagem, algumas reflexões sobre a especificidade desta modalidade teatral se evidenciaram. Uma delas é a postura assumida em relação à distribuição dos personagens. Optamos por não fazer uma divisão rígida dos personagens. Num sentido isto significa que o mesmo personagem pode ser feito por vários atores, seguindo a linha do coringa desenvolvido por Augusto Boal, no trabalho com o Teatro de Arena. Noutro sentido, numa linha mais brechtiana, vários atores faziam um mesmo personagem. Isto, no caso do Teatro em Comunidades, é importante porque a disponibilidade de tempo dos atores não é a mesma do que num trabalho de teatro de grupo ou profissional. As pessoas faltam mais, circulam mais pessoas pelo processo e nem todas podem ficar até o final. São inúmeros os problemas de constância que enfrentamos tanto no grupo do FOFA, como no grupo da Tapera. As pessoas deixam de vir porque o filho está doente, 
porque precisam cuidar do tio, porque passam a estudar num outro período, porque precisam trabalhar naquele horário etc.

Refletindo mais amplamente sobre esta questão e lembrando de trabalhos anteriores, percebo que, sempre que fiz uma divisão rígida de personagens em práticas teatrais comunitárias, enfrentei problemas de não poder ensaiar por faltas de pessoas. Outro exemplo que vem de encontro a esta abordagem é o que acontece nas encenações religiosas. Geralmente consegue-se ensaiar cenas em separado com diferentes grupos da comunidade. As pessoas com mais disponibilidade trabalham mais. O grupo todo só trabalha em conjunto nos ensaios finais, próximos à apresentação. Apesar das divisões, o sentimento de pertencimento faz parte de todos os integrantes. Foi o que fizemos: ensaiamos os adultos na reunião do FOFA e os jovens da comunidade nos dias de estágio (sábados). Uma vez por mês, os dois grupos se encontravam num ensaio na universidade. Essa abordagem mais aberta permite lidar com as tensões típicas desse tipo de teatro com mais tranqüilidade, ao mesmo tempo em que se torna um novo desafio teatral.

A integração entre os dois grupos foi positiva para o Fofa porque criamos um referencial comum que pode reverberar nos diferentes trabalhos desenvolvidos pelos participantes do núcleo. Já para o Grupo da Tapera a peça Relações em Conflito representou um grande amadurecimento em termos teatrais, novos integrantes se juntaram ao grupo que ganhou também maior reconhecimento de sua comunidade.

A peça Relações em Conflito teve várias apresentações ${ }^{14}$, mas a mais importante foi na “Comunidade da Tapera". Transformamos o espaço ao lado da Igreja Católica da comunidade num verdadeiro teatro e o público da comunidade nos deu um retorno muito positivo da apresentação, através de comentários que indicavam como a comunidade se reconheceu na peça.

\footnotetext{
1 Possui graduação em Pedagogia pela Universidade de São Paulo (1980), mestrado em Artes pela Universidade de São Paulo (1993) e doutorado em Drama - University Of Exeter (2002). Atualmente é professora efetiva da Universidade do Estado de Santa Catarina. Tem experiência na área de Artes, com ênfase em Teatro na Comunidade, atuando principalmente nos seguintes temas: teatro em comunidade, teatro para o desenvolvimento.

2 Ver NOGUEIRA, 2002
}

3 Sobre o Agitprop ver GARCIA, Silvana. Teatro de Militância.

4 Ver NOGUEIRA 2002. 
5 Termo cunhado por Richard Chambers.

6 Kidd op cit

7 Sobre codificação imaginária ver o artigo “Buscando uma Interação Teatral poética e dialógica, com a comunidade”. In: Urdimento. No 5, 2003.

8 Sergio de Carvalho é professor do curso de teatro da USP e diretor da Companhia do Latão, um grupo de teatro que tem seu foco no teatro dialético.

9 In: http://fronteiradaslinguagens.blogspot.com/2009/08/sobre-woyzeck-de-buchner.html). Pesquisado em 07/07/2011.

10 O processo criativo da Tapera aconteceu como estágio curricular de teatro em comunidades, feito pelas estágiárias Aline Porto Quites (também bolsista de pesquisa) e Cristina Sanchez (também bolsista de extensão), sob a supervisão da professora Marcia Pompeo Nogueira.

11 Praticamente todos os membros do FOFA participaram.

12 Sobre os conceitos de teatro por e teatro com comunidades, ver o texto "Teatro e Comunidade" in: Telles, Narciso; Florentino, Adilson (org). Cartografias do Ensino de Teatro. Uberlândia: UDUFU, 2009.

$13 \mathrm{O}$ trabalho musical foi desenvolvido por Evanise de Oliveira Figueiredo, João Nogueira Tragtenberg e Paulo de Tarso Lima Brandão, todos músicos membros do FOFA.

14 Apresentamos no Congresso da Arrow, em Plymouth, Inglaterra; na Oficina Intensiva, na UDESC; na Semana de Arte Ousada, na UDESC; no Centro Culrural Amorabi, em Joiville; na Mostra de Teatro do Oprimido de Londrina; na Casa das Máquinas, teatro da lagoa da Conceição, em Florianópolis e na comunidade da Tapera.

\section{REFERÊNCIAS}

BOIA, Lucian. Pour une Histoire de l'Imaginaire. Paris: Les Belles Lettres, 1998.

CARVALHO, Marília. "Quem é negro, quem é branco: desempenho escolar e classificação racial de alunos" in: Revista Brasileira de Educação. Rio de Janeiro, versão impressa disponível no site: http://www.scielo.br/scielo.php?script=sci_arttext\&pid=S1413-24782005000100007

CHAMBERS, R. Whose Reality Counts?: Putting the First Last. Bath: Bath Press, 1997.

FREIRE, Paulo. Conscientização. São Paulo: Cortez e Moraes, 1979.

Teatro do Oprimido. Rio: Paz e Terra, 1977. 
GARCIA, Silvana. Teatro da Militância. São Paulo: Perspectiva, 1990.

KIDD, R., From People's Theatre for Revolution to Popular Theatre for Reconstruction: Diary of a Zimbabwean Workshop. The Hague: CESO, 1984.

MDA, Z., When People play People: development communication through theatre. London: Zed Books, 1993.

NOGUEIRA, Márcia Pompeo. Teatro com Meninas e Meninos de Rua: nos Caminhos do Ventoforte. São Paulo: Perspectiva, 2008. ,"Buscando uma interação teatral poética e dialógica com a comunidade”. In: Urdimento. No.5, 2003. ,"Towards a Poetically Correct Theatre for Development: a Dialogical Approach” Tese de Doutorado, não publicada, Universidade de Exeter, Inglaterra, 2002.

,"Teatro e Comunidade" In: Telles, Narciso; Fiorentino, Adilson. Cartografia do Ensino de Teatro. Uberlândia: UDUFU, 2009 